\title{
Facilitator Psychological Constructs for Mammography Screening among Iranian Women
}

\author{
Parvaneh Taymoori ${ }^{1 *}$, Mahdi Moshki ${ }^{2}$, Daem Roshani ${ }^{3}$
}

\begin{abstract}
Background: While many researchers often use a theoretical framework for mammogram repeat interventions, it seems they do not apply an identified mediation analysis method. The aim of this study was to determine the mediators of mammogram replication behavior in two tailored interventions for non-adherent Iranian women. Materials and Methods: A sample population of 184 women over 50 years old in Sanandaj, Iran, was selected for an experiment. Participants were randomly allocated into one of the three conditions: 1) an intervention based on the Health Belief Model (HBM) 2) an intervention based on an integration of the HBM and selected constructs from the Theory of Planned Behavior (TPB), and 3) a control group. Constructs were measured before the intervention, and after a 6-month follow-up. Results: Perceived self-efficacy, behavioral control, and subjective norms were recognized as mediators in the HBM and selected constructs from the TPB intervention. Perceived susceptibility, severity, barriers, self-efficacy and behavioral control met the criteria for mediation in the HBM intervention. Conclusions: This study was successful in establishing mediation in a sample of women. Our findings enrich the literature on mammography repeat, indicating key intervention factors, and relegating redundant ones in the Iranian populations. The use of strategies to increase mammography repeat, such HBM and TPB constructs is suggested to be important for maintaining a screening behavior, once the behavior has been adopted.
\end{abstract}

Keywords: Mammography repeat - mediators - intervention - Iranian women

Asian Pac J Cancer Prev, 15 (17), 7309-7316

\section{Introduction}

Some reports have documented that regular mammography screening has led to a reduction in breast cancer mortality in women between the ages 50 to 74 about approximately 25-30\% (Yoo et al., 2013). Nevertheless, until 2001, only about half of eligible women have obtained repeat mammography screening (WHO, 2008). It is found that most of them are not screened annually. An estimation declares that from $6-30 \%$ of eligible women receive all available annual mammography over a 5-year or greater time interval (Haber, 2010).

Iranian women are at a mostly high risk for relapse of breast cancer due to lack of appropriate knowledge (Thomas et al., 2011; Samah and Ahmadian, 2012; Charkazi et al., 2013), cancer fear (Lamyian et al., 2007; Heidari et al., 2008; Babu et al., 2011), social manners (Taymoori et al., 2012; Charkazi et al., 2013), painful mammography (Taymoori et al., 2013), embarrassing, and those constraints related to health care and insurance systems (Keshavarz et al., 2011; Fouladi et al., 2013). Iranian women have also particular social beliefs that may influence motivation for preventive medicine, such as cultural beliefs, fatalism, and devoting themselves over the family as they get older (Lamyian et al., 2007; Taymoori et al., 2012).

The Health Belief Model (HBM) is being applied by most Iranian researchers as a framework to recognize factors contributing to screening decisions (Montazeri A et al., 2003; Ahmadian et al., 2012) (Champion et al., 2005). According to the HBM, perception of individual threat plays a key role as a source of motivation for health behaviors. Whether cancer fear prevents or encourages screening behaviors, it has posited concerns in recent years (Hay et al., 2005). There are four hypotheses related to cancer threat for screening behaviors: $i$ ) the role of facilitators, $i i$ ) the role of barriers, $i i i$ ) exerting a moderate level of cancer threat may improve screening, and $i v$ ) promote screening (Hay et al., 2005). For example, the Extended Parallel Process Model (EPPM) hypothesizes that the people who have pessimistic beliefs, are most vulnerable to a health danger and others who have a high perceived control on their health, are most likely to take screening behavior acts (Witte, 1992).

Several studies have shown that increased risk perception and disease fear may not lead to the promotion

${ }^{1}$ Kurdistan Environmental Health Research Center, ${ }^{3}$ Kurdistan Research Center for Social Determinants of Health, School of Medicine, Kurdistan University of Medical Sciences, Kurdistan, ${ }^{2}$ Department of Public Health, School of Health, Social Development \& Health Promotion Research Center, Gonabad University of Medical Sciences, Gonabad,Iran *For correspondence: parvaneh_tay@ yahoo.com 
of preventive behaviors (Consedine et al., 2004; Hay et al., 2006; Al-Naggar and Bobryshev, 2012) and in some cases result in conditions such as resistance or fatalism in the face of disease (Baron-Epel et al., 2009). The HBM ignores the social and environmental factors like social norms concerning the interactions between the individual and the environment, and focuses primarily on the role of intrapersonal individual (Glanz et al., 2008). The low influence of current interventions on mammography screening in Iranian women (Hajian et al., 2011) may be linked to using these factors. Investigation of Iranian women's insights concerning control and prevention of breast cancer suggests three main factors including; $i$ ) attitudes, beliefs, and feelings like inattention, low selfefficacy, fear of cancer, fatalism, ii) social net practices (e.g. useless health communication, getting supports from family members), and ii) availability and accessibility of services and supports dedicated by government and community like coverage rate, suitable places and easy transportation (Lamyian et al., 2007; Thomas et al., 2011). Whereas HBM does not characterize such main Iranian cultural values, the Theory of Planned Behavior (TPB) may help as a useful framework to deal with key contextual and interpersonal factors related to mammography screening choices. This can be achieved through combination of cultural features as subjective norms (Fishbein, 1975; Poss, 2001) and the opinion of external factors as perceived behavioral control (Godin et al., 2001). Iranian culture regards the importance of interdependence and interconnection between people and groups (Keshavarz et al., 2011). According to Ahmadian's study, mammography practices among Iranian women is associated with social influence (Ahmadian et al., 2012). As there is no primary prevention strategy for breast cancer in Iran, therefore, the capacity to get a mammogram often depends on external factors like provider health care recommendations. Recent studies conducted among Iranian women have also showed that awareness of external factors may simplify mammography usage (e.g., giving information about community screening services) (Montazeri et al., 2008; Ahmadian et al., 2011). It is discussed that the low effectiveness and utility of interventions may be linked to a lack of awareness concerning the mechanisms in charge for $\mathrm{BC}$ screaming behaviors. In the last decade, the importance placed on theory when planning interventions has increased (Moodi et al., 2012; Charkazi et al., 2013; Yoo et al., 2013). While researchers frequently refer to a theoretical framework (e.g. HBM or TBP), no studies accomplish a mediation analysis to identify whether increases in rate of repeating mammography were a result of changes in the theoretical framework. To our knowledge, only one study conducted a mediation analysis to identify the mediators to obtain a mammogram among Chilean women. It found that getting a mammography was a result of an increase in self- efficacy (Molina et al., 2013).

Additional study is required to develop more effective and efficient interventions by recognizing the components of interventions that are accountable for repeat of mammography behavior. The aim of this paper was to represent mediators of obtaining mammogram repeat in two 6-month tailored mammography interventions in Iranian women. The first intervention was based on Health Belief Model and the second one integrated two constructs from the Planned Behavior Theory into the HBM. It was expected that a specific tailored intervention based on the HBM that combines additional constructs from the $\mathrm{TPB}$, would result in increased adherence compared to an intervention exclusively based on the HBM. It was also hypothesized that the perceived control and subjective norms would mediate repeated mammography in the TPB intervention, but not in the HBM intervention.

\section{Materials and Methods}

Our health care study centers were all from Sanandaj, a city that has a wide range of social and economic conditions. Using a table of random numbers, three of nineteen healthcare centers were randomly selected as recruitment sites. A list of women over 50 years old from each clinic was selected and then contacted by phone or through a home visit, if their phone number not available. Approximately 244 women were screened for the following eligibility criteria: no history of breast cancer; a history of a mammogram within the past 2-3 years; no intention to obtain a mammogram within the next year; and an ability to read and write. Fifty-five women did not participate in the study. Of these women, eighteen women refused to participate. The remaining women were ineligible for the study, because they had never obtained a mammogram $(n=22)$ or were planning to obtain a mammogram $(n=15)$. Prior to participation, investigators sent a written information sheet and consent form for the women to sign. After consenting to participate in the study, 190 individuals were randomly assigned to either to one of three conditions: a tailored intervention based on the HBM that included constructs from the TPB $(n=60)$, an intervention based on the HBM $(n=63)$ and a control (CON) group $(n=61)$. Follow up was done by 184 volunteers as six participants were unable to be reached after the end of the intervention to complete follow-up questionnaires. All survey questionnaires described below were administered to three groups prior to and six months following the intervention. The Ethical Committee of Kurdistan University of Medical Sciences approved the study.

The questionnaire used in this study was based on Champion's revised Health Belief Model Scale (CHBMS) and selected constructs from the TPB including subjective norms and perceived control. In previous research, the perceived severity and susceptibility scales showed reliability coefficients of 0.82 and 0.84 , respectively. In the current study, the Cronbach's alpha coefficients were 0.72 and 0.73 for the perceived benefits and barriers scales, respectively (Taymoori and Berry, 2009). The studied socio-demographic items were age, marital status, employment status, educational level, family history of breast cancer, and participant's health insurance.

Belief statements were rated on a 4-point scale from 1 (strongly disagree) to 4 (strongly agree) and scored by calculating the means of all item scores. Perceived susceptibility was assessed using a 3-item scale. The 
participants were asked to respond to a 7-item scale to measure perceived severity. Perceived benefits and perceived barriers of mammography were also measured on 6 and 9-item scales, respectively.

Perceived self-efficacy was adapted from an existing mammography self-efficacy scale (Champion et al., 2005). This scale included ten items (e.g., I can arrange transportation to get a mammogram) which were rated on a 4-point Likert scale ranging from 1 (not at all confident) to 4 (very confident). Cronbach's alpha value for the selfefficacy score was 0.90 .

Subjective norms were assessed using a question by asking: "most of the people who are significant to you, expect that you must get a mammogram when you are due?" on a 4-point scale ranging from 1(never) through 4 (often).

Perceived control was assessed using the item: "How much control do you have over whether you get a mammogram when you are due?" rated on a 4-point scale ranging from 1 (never) through 4 (often).

The test-retest reliability coefficients taken over a 2 -week period for subjective norms and perceived control were 0.84 and 0.87 , respectively $(n=73)$.

\section{Educational programs of intervention}

The educational programs took place within the health care centers. Both interventions included education and individual counseling sessions. There were eight sessions for the HBM and TPB interventions that focused on perceived threat (i.e., perceived susceptibility/ seriousness of breast cancer), benefits and barriers of mammography and self-efficacy. Session formats included multimodal lectures with educational resources (films, slides pamphlets). Individual components of sessions were tailored to women's specific needs, which were identified through the baseline surveys. Each participant received eight 45-60 minute group sessions at $1-6^{\text {th }}, 8-9^{\text {th }}$ and $10-13^{\text {th }}$ weeks. During these sessions, participants were divided into groups based on their reported common woman's requirements obtained and intervention education sessions took place in groups of 5 to 12 women. Group sessions allowed for active learning through small group discussions and exposure modeling (e.g., role modeling with breast cancer survivors). The TPB group received four additional sessions in subjective norms and perceived behavioral control. Furthermore, the control group received pamphlets after they completed the follow-up questionnaire. Pamphlets included the following information: risk factors for breast cancer, benefits of early detection breast cancer by mammography, the recommended guidelines for mammography screening according.

\section{Hypothesized mediators of physical activity behavior}

Seven following potential mediators are assessed in this study: perceived susceptibility, severity, benefits, barriers, self-efficacy, behavioral control and subjective norms. Mediation will be found if there is a significant indirect correlation between an intervention and an outcome after controlling for the mediator (Baron and Kenny, 1986).

\section{Data analysis}

The data were analyzed using a macro for SPSS (Preacher and Hayes, 2004), which facilitates the estimation of indirect effects with a normal theory approach and a bootstrap approach to obtain confidence intervals as well as to examine the indirect effects using Sobel test (Sobel, 1982). In addition, by applying the product-of-coefficients (POC) test, which is based on the criterion identified by (Baron and Kenny, 1986), the indirect effect estimation using 5000 bootstrap samples was also calculated. The Outcome variable was categorized into $0=$ not repeating mammogram, and $1=$ repeating mammogram. Outcomes were measured at baseline and 6 months after the intervention. To control the group differences at baseline, score changes (by subtracting follow-up score from baseline score) were used in all analyses. Both interventions (HBM and TPB) were compared to the control group in separate analyses to assess mediation effect.

\section{Results}

At baseline, the participants were on average 55.93 years old $(\mathrm{SD}=7.80)$. Approximately, $47 \%$ were under high school education and $52 \%$ were not currently employed; nonetheless, more than two thirds had good/ very good salaries and were married. Most of them had health insurance $(85 \%)$, only $7 \%$ reported that had no breast problems in the past five years, and only $11 \%$ had family history of breast cancer. The majority of socio-demographic and clinical variables did not vary across groups (data not shown). Nevertheless, there were

Table 1.Specific Values for Pretest, Posttest, and Change Scores for Mammography Screening and Hypothesized Mediators among Iranian Women

\begin{tabular}{|c|c|c|c|c|c|c|c|c|c|}
\hline \multirow[b]{2}{*}{ Hypothesized mediators } & \multicolumn{3}{|c|}{ Baseline } & \multicolumn{3}{|c|}{ Six Months Follow-Up } & \multicolumn{3}{|c|}{ Change Scores } \\
\hline & $\operatorname{TPB}(n=60)$ & $\operatorname{HBM}(n=63)$ & $\operatorname{CON}(n=61)$ & $\operatorname{TPB}(\mathrm{n}=60)$ & $\operatorname{HBM}(n=63)$ & $\operatorname{CON}(\mathrm{n}=61)$ & $\mathrm{TPB}(\mathrm{n}=60)$ & $\operatorname{HBM}(n=63)$ & $\mathrm{CON}(\mathrm{n}=61)$ \\
\hline Perceived susceptibility & $3.36(0.79)$ & $3.38(1.03)$ & $3.04(0.96)$ & $3.66(1.42)$ & $4.20(0.61)$ & $3.19(1.01)$ & $0.30(1.50)$ & $0.82(1.18)$ & $0.14(1.23)$ \\
\hline Perceived severity & $2.94(0.76)$ & $2.97(0.99)$ & $2.66(0.99)$ & $3.36(1.32)$ & $3.77(0.83)$ & $2.80(0.78)$ & $0.42(1.62)$ & $0.79(1.17)$ & $0.14(1.16)$ \\
\hline Perceived benefits & $2.81(0.57)$ & $2.61(0.65)$ & $2.73(0.64)$ & $3.31(0.83)$ & $3.54(0.50)$ & $3.25(0.39)$ & $0.50(1.09)$ & $0.93(0.79)$ & $0.52(0.67)$ \\
\hline Perceived barriers & $2.70(0.53)$ & $2.89(0.55)$ & $2.89(0.53)$ & $1.79(0.56)$ & $1.79(0.41)$ & $2.22(0.58)$ & $-0.90(0.89)$ & $-1.10(0.67)$ & $-0.67(0.62)$ \\
\hline Perceived self-efficacy & $1.47(0.44)$ & $1.48(0.48)$ & $1.43(0.42)$ & $2.43(0.82)$ & $2.58(0.69)$ & $1.85(0.55)$ & $0.95(0.93)$ & $1.10(0.85)$ & $0.41(0.64)$ \\
\hline Perceived behavioral control & $11.61(0.54)$ & $1.62(0.38)$ & $1.61(0.29)$ & $2.36(0.41)$ & $2.17(0.46)$ & $1.81(0.51)$ & $0.75(0.63)$ & $0.55(0.57)$ & $0.20(0.57)$ \\
\hline Subjective norms & $2.88(0.76)$ & $2.79(0.82)$ & $2.88(0.87)$ & $3.68(0.30)$ & $3.37(0.82)$ & $3.05(0.59)$ & $0.79(0.83)$ & $0.58(1.10)$ & $0.16(0.89)$ \\
\hline Obtained mammogram & & & & $\mathrm{N}(\%) 39(65)$ & $\mathrm{N}(\%) 37(59)$ & $\mathrm{N}(\%) 14(23)$ & & & \\
\hline
\end{tabular}

*CON, Control group; HBM, Intervention based on Health Belief model; $\mathrm{n}(\%)$; means and standard deviations shown in brackets; N, number of women who reported obtaining a mammogram within six months following the 
significant differences in marital status, $\chi^{2}(2)=17.69$, $\mathrm{p}<0.001$.

Values for pretest, posttest, and change scores for mammography screening related to beliefs and hypothesized mediators are shown in Table 1. At first, the effect of the treatment condition on mammography repeat was tested. When the data in the TPB group were compared to the CON group, a significant intervention effect was identified $(\mathrm{p}<0.0001)$. Similarly, when the HBM group results were compared to the CON group, $(p<0.0001)$ the first criterion for mediation was met. The criteria for mediation in the TPB intervention were established for all variables. Linear regression analysis revealed that the intervention group showed increased perceived susceptibility and severity $(\mathrm{p}<0.002$ and $\mathrm{p}<0.001)$, respectively. Those in the intervention group presented higher self-efficacy $(\mathrm{p}<0.0001)$, perceived benefits $(\mathrm{p}<.002)$, also fewer barriers to mammography $(\mathrm{p}<0.0003)$ at follow-up. This is surprising because increased behavior control and subjective norms were $(\mathrm{p}<0.0001$ and $\mathrm{p}<0.01)$, respectively.

Next, the association between treatment condition and changes in hypothesized mediators in the HBM intervention was examined. Linear regression analysis showed that the intervention group reported increased self-efficacy $(p<0.00003)$, perceived behavioral control $(\mathrm{p}<0.0001)$, and also subjective norms $(\mathrm{p}<0.001)$ at follow-up. There were no statistically significant differences between intervention and control groups for any of the hypothesized mediators (i.e. perceived susceptibility, severity, benefits and barriers).

The relationship between changes in the hypothesized mediators and changes in getting mammography was

Table 2. Effect of Mediator Variables and Treatment on Mammography Repeat in TPB Intervention

\begin{tabular}{lccllcr}
\hline Hypothesized mediators & \multicolumn{2}{c}{$\mathrm{M}$} & & \multicolumn{2}{c}{$\mathrm{X}$} \\
\cline { 2 - 3 } \cline { 6 - 7 } & $\begin{array}{c}\text { Beta } \\
\text { Coefficient (SE) }\end{array}$ & & & $\begin{array}{c}\text { Beta } \\
\text { Coefficient (SE) }\end{array}$ \\
\hline Perceived susceptibility & $0.504(0.19)$ & $2.55^{*}$ & & $2.61(0.45)$ & $5.74^{* *}$ \\
Perceived severity & $0.519(0.21)$ & $2.45^{*}$ & & $2.60(0.45)$ & $5.75^{* *}$ \\
Perceived benefits & $0.830(0.34)$ & $2.42^{*}$ & $2.93(0.48)$ & $6.03^{* *}$ \\
Perceived barriers & $-1.65(0.42)$ & $-3.92^{* *}$ & $2.60(0.48)$ & $5.35^{* *}$ \\
Perceived self-efficacy & $3.80(0.76)$ & $4.99^{* *}$ & $3.21(0.76)$ & $4.20^{* *}$ \\
Perceived behavioral control & $1.60(0.48)$ & $3.32^{* *}$ & $2.89(0.50)$ & $5.70^{* *}$ \\
Subjective norms & $0.463(0.21)$ & $2.11^{*}$ & $2.66(0.44)$ & $5.92^{* *}$ \\
\hline
\end{tabular}

*M, mediators; Se, standard error; TPB, intervention based on the health belief and planned behavior models; $\mathrm{t}$, direct effect; $\mathrm{x}$, treatment $* * \mathrm{p}<0.0001$

Table 3. Effect of Mediator Variables and Treatment on Mammography Repeat in HBM Intervention

\begin{tabular}{lcclll}
\hline Hypothesized mediators & \multicolumn{2}{c}{$\mathrm{M}$} & & \multicolumn{2}{c}{$\mathrm{X}$} \\
\cline { 2 - 3 } \cline { 5 - 6 } & $\begin{array}{c}\text { Beta } \\
\text { Coefficient (SE) }\end{array}$ & & & $\begin{array}{c}\text { Beta } \\
\text { Coefficient (SE) }\end{array}$ & $\mathrm{t}$ \\
\hline Perceived susceptibility & $1.09(0.22)$ & $4.90^{* *}$ & $1.06(0.19)$ & $5.47^{* *}$ \\
Perceived severity & $0.911(0.20)$ & $4.40^{* *}$ & $0.971(0.18)$ & $5.39^{* *}$ \\
Perceived benefits & $1.18(0.31)$ & $3.79^{* *}$ & $1.00(0.17)$ & $5.78^{* *}$ \\
Perceived barriers & $-2.09(0.44)$ & $-4.69^{* *}$ & $1.00(0.19)$ & $5.24^{* *}$ \\
Perceived self-efficacy & $2.83(0.55)$ & $5.14^{* *}$ & $0.831(0.20)$ & $4.05^{* * *}$ \\
Perceived behavioral control & $2.28(0.55)$ & $4.51^{* *}$ & $0.715(0.17)$ & $4.19^{* *}$ \\
Subjective norms & $0.695(0.27)$ & $2.52^{*}$ & $0.736(0.14)$ & $4.93^{* *}$ \\
\hline
\end{tabular}

*M, mediators; Se, standard error; TPB, intervention based on the health belief and planned behavior models; $\mathrm{t}$, direct effect; $\mathrm{x}$, treatment $* * \mathrm{p}<0.0001$
Table 4. Effect of Mediator Variables on Mammography Repeat in TPB Intervention among Iranian Women

\begin{tabular}{lccc}
\hline Hypothesized mediators & Beta Coefficient (SE) & CI & Z \\
\hline Perceived susceptibility & $0.056(0.09)$ & -0.364 & 0.601 \\
Perceived severity & $0.086(0.08)$ & -0.32 & 1.05 \\
Perceived benefits & $0.013(0.068)$ & -0.146 to- 0.118 & -0.204 \\
Perceived barriers & $0.160(0.105)$ & -0.411 & 1.53 \\
Perceived self-efficacy & $0.508(0.17)$ & 0.172 to- 0.843 & $2.96^{* *}$ \\
Perceived behavioral control & $0.422(0.12)$ & 0.174 to 0.671 & $3.33^{* *}$ \\
Subjective norms & $0.147(0.06)$ & 0.010 to -0.283 & $2.10^{*}$ \\
\hline
\end{tabular}

*CI, confidence interval; Se, standard error; TPB, intervention based on the health belief and planned behavior models; $\mathrm{t}$, direct effect; $\mathrm{x}$, treatment; $\mathrm{z}$, indirect effect $* \mathrm{p}<0.03 ; * * \mathrm{p}<0.001-0.0001$

Table 5. Effect of Mediator Variables on Mammography Repeat in HBM Intervention

\begin{tabular}{lccc}
\hline Hypothesized mediators & Beta Coefficient (SE) & CI & Z \\
\hline Perceived susceptibility & $0.340(0.17)$ & -0.005 to 0.687 & $1.92^{*}$ \\
Perceived severity & $0.341(0.18)$ & -0.013 to 0.696 & $1.88^{*}$ \\
Perceived benefits & $0.349(0.18)$ & -0.018 to 0.718 & 1.85 \\
Perceived barriers & $0.713(0.26)$ & 0.188 to 1.23 & $2.66^{* *}$ \\
Perceived self-efficacy & $2.600(0.73)$ & 1.150 to 4.05 & $3.52^{* *}$ \\
Perceived behavioral control & $0.550(0.25)$ & 0.142 to 1.15 & $2.51^{*}$ \\
Subjective norms & $0.197(0.13)$ & -0.058 to 0.454 & 1.51
\end{tabular}

*Abbreviations: CI, confidence interval; HBM, intervention based on the health belief model; Se, standard error; $t$, direct effect; $x$, treatment; $z$, indirect effect $\mathrm{p}$ $<0.05 ; * * \mathrm{p}<0.001-0.0001$

tested in the next step. These changes are showed by separate coefficients which hypothesized the mediators and treatment conditions in Tables 4 and 5 for TPB and HBM groups, respectively.

The final step was to determine if the relationship between the intervention and repeat mammography was significant after controlling for the mediators or not. Treatment condition (TPB and HBM) and hypothesized mediators were entered into regression models explaining changes in getting mammography.

The significant indirect effect was found for perceived self-efficacy $p<0.003$ in the TPB intervention. However, the same results were seen for perceived behavioral control $\mathrm{p}<0.0009$, and subjective norms $(\mathrm{p}<0.03)$. Changes in any hypothesized mediators could not satisfy the criteria for mediation.

In the HBM intervention, there was a significant indirect effect for perceived self-efficacy $(p<0.0004)$, barriers $(\mathrm{p}<0.007)$, susceptibility and severity $(\mathrm{p}<0.05)$. Furthermore, the difference in perceived behavior control was significant $(\mathrm{p}<0.01)$ suggesting that it satisfied the fourth criterion for mediation.

\section{Discussion}

Our results indicated changes in perceived barriers as mediating mammography repeat behavior in the HBM intervention. The previous research among nonadherent women has suggested the relationship between cognitions regarding the perceived barriers and repeat of mammography, (Ajzen, 2005; Burke et al., 2009; Gierisch et al., 2010b) and also having intention to maintain mammogram adherence (O'Neill et al., 2008). While both intervention groups received similar education programs regarding the barriers of getting mammography, perceived 
barriers did not satisfy the criteria for mediation in the TPB intervention. The identified perceived barriers as a mediator in the current study may be related to the studied participants, who were Iranian women. It may be that Iranian women have not been provided with the individual messages regarding overcoming the barriers of regular mammography from health care providers. Separating the common personal and environmental barriers to get mammography was as intervention component. Individual counseling to provide tailored messages on strategies to overcome perceived barriers (e.g., not knowing how to get a mammography, making appointment with an appropriate mammogram center) is helpful in promoting regular mammography adoption when participants are due to obtain the test and do not have a plan to do it (Russell et al., 2006; Gierisch et al., 2010b). It is possible that the added information regarding mammogram benefits and self-efficacy received by individuals in the HBM group, contribute to decreased perceptions regarding the mammography repeat barriers, which in turn, help mediate getting mammography. Applying of structural equation modeling may be advantageous to explain these relationships in future studies.

It was also shown that changes in self-efficacy mediated changes in obtaining mammography in both interventions (TPB and HBM). Gierisch's study revealed lower self-efficacy as longitudinal predictor among nonadherence to maintenance mammography (Gierisch et al., 2010b). In a recent study, Molina showed that selfefficacy mediated the relationship between the importance of receiving recommendations and plans to obtain mammogram (Molina et al., 2013). Self-efficacy also is found as the most significant predictor of mammography intention (Tolma et al., 2006). Perceived barrier is another concept linked to self-efficacy (Glanz et al., 2008), which refers to actual or visualized difficulties of a regular breast cancer screening. It is possible that increasing selfefficacy in the intervention groups was also connected with a reduction in perceived barriers, which meet the criteria as a mediation variable. Results of a study by Rutter also supported the importance of self-efficacy in the clarification of intention to get a mammogram (Rutter, 2000). These results suggest that enhancing women's self-efficacy may increase individual abilities to overcome physical as well as psychological obstacles to be encountered on scheduled screening mammography. (Burke et al., 2009; Molina et al., 2013).

Personal behavioral control beliefs consist of two categories: (a) internal issues e.g. knowledge, capacities, and feeling, and (b) external factors such as circumstances and environmental issues of a person (Ajzen, 2005). Some attempts were made in education sessions to convey to them the belief that they are responsible for their breast health and to increase skills on how to resolve environmental encounters (e.g., physician appointment, asking for a mammogram prescription from their doctors) (Ajzen, 2002). On the other hand, self-efficacy is concerned with the perceived confidence in the ability to get a mammogram, focusing mainly on internal factors. As it was expected, perceived behavioral control was found as mediator in TPB group, but not in
HBM intervention. Given that there is no population prevention approach for breast cancer in Iran, it is not surprising that getting a mammogram often relies on external as well as internal factors as supported by our results. In contrast, in those populations that have easy access to mammography and insurance health services, the lower contribution of perceived behavioral control proposes that increased self-efficacy is more likely to impact getting mammogram than environmental factors (perceived behavioral control) (Povey et al., 2000; Tolma et al., 2006). The contribution of mediation roles of the behavioral control in HBM may also be related to the positive link between self-efficacy and perceived control which is supported in literature (Povey et al., 2000; Ajzen, 2002).While the interactions of self-efficacy and control ability are not assessed in the study, this finding implies such connections. Nevertheless, more investigations are needed to examine the relations of the two constructs in various settings and populations related to repeat breast cancer screening. The role of mediation of the behavioral control in HBM may be also related to the link between perceived control and reduced mammography barriers and increasing mammogram repeat benefits which needs to be documented by empirical researches.

Changes in perceived subjective norms were found to mediate behavior changes in the TPB intervention. This is a unique finding of previous research that has suggested the role of family members, friends and providers to obtain a mammogram (Garbers and Chiasson, 2004; Allen et al., 2008; Guvenc et al., 2012), maintenance mammography (Allen et al., 2008; Gierisch et al., 2010a), predictor intention to get a mammogram as well as initial mammogram (Rutter, 2000; Godin G et al., 2001). Other findings supported the relationship between subjective norms and the intention to maintain adherence to mammography (O'Neill et al., 2008). Moreover, one study evaluating the meditational effect of subjective norms showed that provider recommendations mediated a link between breast cancer risk perception and family history of cancer to repeat mammography. In another research, Molina found that family recommendations were connected with plans to get a mammogram by improving self-efficacy (Molina et al., 2013). Although providing and receiving the recommendations to be on scheduled mammography behavior does not guarantee it. It is noted that family and friend recommendations were accepted as a reminder as well as a source of information to get a mammogram among adherent women to monitor via screening mammography (Fernandez et al., 2005; Luquis RR and IJ., 2006). The identification of perceived subjective norms as a mediator in the current study may also be associated with the study of women having Iranian culture. May be Iranian women have not been provided with strong messages (memos) regarding the recommendations to get a mammogram on the behalf of family members, friends or providers. Such information is useful in sustaining screening behaviors adoption when participants are due to.

Results related to the role of perceived threat or risk is mixed. Some previous studies showed that the low risk perception keeps on influencing future mammography 
adherence (Rakowski et al., 2004; Fernandez et al., 2005; Rakowski et al., 2006), while the other studies found there is more likely to be adherence to mammogram if there is high perceived risk or threat (Consedine et al., 2004; Luquis and Cruz, 2006; $\mathrm{H}$ et al., 2011). There are some proposed issues related to perceived risk that may affect perceived risk, for example: optimistic bias versus overestimation, confounding effects of recruitment setting, and measurement (Luquis and Cruz, 2006). Ignoring these biases in estimation of perceived risk of breast cancer, there is also the possibility that cancer risk perception interacts with some psychosocial and demographic factors. The results of such interactions were found in mammography behavior literature. For example, Katapodi showed having a family history for breast cancer, race, culture and worry affected breast cancer risk perception (Katapodi et al., 2004). The perceived susceptibility and severity in the presence of perceived control mediated replicate mammography in HBM group, while in TPB group perceived susceptibility and severity didn't satisfy the role of mediating. There are some possible explanations for this result; first, reciprocal association between subjective norms (such as getting recommendation from family or providers to having mammography regularly) and perceived risk that may be influenced mammography repeat in TPB group, probably not seen in HBM group. Additionally, it is found that physician recommendation was as a moderator of the relationship between risk perception and repeat mammography (Haber, 2010). So, it may be implied that the mediating role of subjective norms which impacted on perceived risk was not recognized as a mediator factor in TPB intervention. Second, we didn't assess interactions between risk concept and family history of breast cancer that possibly resulted in differentiated outcome in groups related to the role of mediating of risk perception. Recently, Habar's study detected a positive association between breast cancer risk perception and repeat mammography by family history of cancer using structural equation model (Fishbein M and I, 1975). Finally, it should be noted that we didn't assess reciprocal relationships between risk perception and the other cognitive concepts such as self-efficacy, social support, demographic features, cultural conditions, accessibility, and health service factors that may affect our results. More investigations are needed in order to obtain much clearer interpretations related to these interactions and their effects on replicate mammogram among diverse populations.

There are a number of limitations that should be noted. First, the sample size was not large enough to discover minor changes in the hypothesized mediators, though the power calculation based on the Sobel test recommended that a sample size of 90 was needed to establish mediation. Based on a medium effect size, further constructs may have met mediation in a larger sample. Second, this study included only participants who didn't have a plan to replicate mammogram, did not involve women without a history of having mammogram, and women not wanting or intending to obtain mammography.

There are some novel points to which attention should be paid in this study. First, this study achieved the criteria for establishing mediation in a sample of women. Second, it was found that the maximum intervention assessed, improved repeat of mammography intention by $23-25 \%$ compared to the control group.

Beliefs about overcoming barriers would predict long-term adherence mammography. Providing tailored counseling to overcome the individual barriers helped promoting repeat of mammography while participants had no plan to do it. The women's self-efficacy satisfied the criteria for mediation, suggesting that the intervention components designed to increase self-efficacy, were necessary or effective in facilitating getting mammogram. A unique feature of this research was the involvement of the participant's family with the intention of changing cultural norms and providing messages for the participants through others to encourage obtaining mammogram. Considering that there is no population prevention plan for breast cancer in Iran, our results provided additional support for the efficacy of perceived behavioral control to increase mammography repeat.

The authors propose that the impact of interventions on these constructs may be due to uniqueness of the study women, who were not adherent candidates for regular mammography. While changes in outcome and efficacy beliefs mediated mammography replicate behavior in the study sample, it is not supposed that these findings can be applicable in Western societies. For example, it is hypothesized that the social norms mediated getting mammogram in the current study, because Iranian women have not been getting mammogram messages reinforced through the family or friends, to the same extent as their Western counterparts.

\section{Acknowledgements}

We thank the Deputy of Research and Technology of Kurdistan University of Medical Sciences for providing financial supports. The authors have no funding or conflicts of interest to disclose.

\section{References}

Ahmadian M, Samah AA, Redzuan Mr, et al (2011). Barriers to mammography among women attending gynecologic outpatient clinics in Tehran, Iran. J Scientific Res Essays, 6, 5803-11.

Ahmadian M, Samah AA, Redzuan Mr, et al (2012). Predictors of mammography screening among Iranian women attending outpatient clinics in Tehran, Iran. Asian Pac J Cancer Prev, 13, 969-74.

Ajzen I (2002). Perceived behavioral control, self efficacy, locus of control, and the theory of planned behavior. J Applied Social Psychology, 32, 665-83.

Ajzen I 2005. Attitudes, Personality, and Behavior. McGrawHill International.

Al-Naggar RA, Bobryshev YV (2012). Practice and barriers of mammography among Malaysian women in the general population. Asian Pac J Cancer Prev, 13, 3595-600.

Allahverdipour H, Asghari-Jafarabadi M, Emami A (2011). Breast cancer risk perception, benefits of and barriers to mammography adherence among a group of Iranian women. Women Health. 51, 204-19.

Allen JD, Stoddard AM, Sorensen G (2008). Do social network characteristics predict mammography screening practices? 
Health Education \& Behavior, 35, 763-76.

Babu GR, Samari G, Cohen SP, et al (2011). Breast cancer screening among females in Iran and recommendations for improved practice: a review. Asian Pac J Cancer Prev, 12, 1647-51.

Baron-Epel O, Friedman N, Lernau O (2009). Fatalism and mammography in a multicultural population. Oncology nursing forum. Onc Nurs Society, 353-61.

Baron RM, Kenny DA (1986). The moderator-mediator variable distinction in social psychological research: Conceptual, strategic, and statistical considerations. J Personality Social Psychol, 51, 1173.

Burke NJ, Bird JA, Clark MA, et al (2009). Social and cultural meanings of self-efficacy. Health Education Behavior, 36, 111-28.

Champion V, Skinner CS, Menon U (2005). Development of a self efficacy scale for mammography. Res Nursing Health, 28, 329-36.

Charkazi A, Samimi A, Razzaghi K, et al (2013). Adherence to Recommended Breast Cancer Screening in Iranian Turkmen Women: The Role of Knowledge and Beliefs. ISRN Prev Med, doi: 10.5402/2013/581027. eCollection 2013.

Consedine NS, Magai C, Krivoshekova YS, et al (2004). Fear, anxiety, worry, and breast cancer screening behavior: a critical review. Cancer Epidemiology Biomarkers Prevention, 13, 501-10.

Fernandez ME, Palmer RC, Leong-Wu CA (2005). Repeat mammography screening among low-income and minority women: a qualitative study. Cancer Control, 12, 77-83.

Fishbein MI A (1975). Belief, attitude, intention and behavior: An introduction to theory and research.

Fouladi N, Pourfarzi F, Mazaheri E, et al (2013). Beliefs and behaviors of breast cancer screening in women referring to health care centers in northwest Iran according to the Champion health belief model scale. Asian Pac J Cancer Prev, 14, 6857-62.

Garbers S, Chiasson M (2004). Patterns of agreement on breast cancer screening knowledge and practices among women in Dominican and Mexican families in New York City. Med Sci Monitor, 10, 628.

Gierisch JM, DeFrank JT, Bowling JM, et al (2010a). Finding the minimal intervention needed for sustained mammography adherence. Am J Preventive Med, 39, 334-44.

Gierisch JM, Earp JA, Brewer NT, et al (2010b). Longitudinal predictors of nonadherence to maintenance of mammography. Cancer Epidemiology Biomarkers Prevention, 19, 1103-11.

Glanz K, Rimer BK, Viswanath K 2008. Health behavior and health education: theory, research, and practice, San Francisco Jossey-Bass.

Godin G, Gagné C, J M, et al (2001). Breast cancer: The intention to have a mammography and a clinical breast examinationapplication of the theory of planned behavior. Psychology and Health, 16, 423-41.

Guvenc I, Guvenc G, Tastan S, et al (2012). Identifying women's knowledge about risk factors of breast cancer and reasons for having mammography. Asian Pac J Cancer Prev, 13, 4191-7.

Haber G (2010). Use of structural equation modeling to examine the association between breast cancer risk perception and repeat screening mammography among United States women.

Hajian S, Vakilian K, Najabadi KM, et al (2011). Effects of education based on the health belief model on screening behavior in high risk women for breast cancer, Tehran, Iran. Asian Pac J Cancer Prev, 12, 49-54.

Hay JL, Buckley TR, Ostroff JS (2005). The role of cancer worry in cancer screening: a theoretical and empirical review of the literature. Psycho Oncol, 14, 517-34.
Hay JL, McCaul KD, Magnan RE (2006). Does worry about breast cancer predict screening behaviors? A meta-analysis of the prospective evidence. Preventive Med, 42, 401-8.

Heidari Z, Mahmoudzadeh-Sagheb HR, Sakhavar N (2008). Breast cancer screening knowledge and practice among women in southeast of Iran. Acta Medica Iranica, 46, 321-8.

Katapodi MC, Lee KA, Facione NC, et al (2004). Predictors of perceived breast cancer risk and the relation between perceived risk and breast cancer screening: a meta-analytic review. Preventive Medicine, 38, 388-402.

Keshavarz Z, Simbar M, A. R (2011). Factors for performing breast and cervix cancer screening by Iranian female workers: a qualitative-model study. Asian Pac J Cancer Prev, 12, 1517-22.

Lamyian M, Hydarnia A, Ahmadi F, et al (2007). Barriers to and factors facilitating breast cancer screening among Iranian women: a qualitative study. Eastern Mediterranean Health $J, \mathbf{1 3}, 1160-9$.

Luquis RR, IJ VC (2006). Knowledge, attitudes, and perceptions about breast cancer and breast cancer screening among Hispanic women residing in South Central Pennsylvania. $J$ Community Health, 31, 25-42.

Luquis RR, Cruz IJV (2006). Knowledge, attitudes, and perceptions about breast cancer and breast cancer screening among Hispanic women residing in South Central Pennsylvania. J Comm Health, 31, 25-42.

Molina Y, Martinez-Gutierrez J, Puschel K, et al (2013). Plans to obtain a mammogram among Chilean women: the roles of recommendations and self-efficacy. Health Educ Res, 28, 784-92.

Montazeri A, Haji-Mahmoodi M (2003). Breast self-examination: do religious beliefs matter? A descriptive study. J Public Health Med, 25, 154-5.

Montazeri A, Vahdaninia M, Harirchi I, et al (2008). Breast cancer in Iran: need for greater women awareness of warning signs and effective screening methods. Asia Pac Fam Med, 7, 6 .

Moodi M, Rezaeian M, Mostafavi F, et al (2012). Determinants of mammography screening behavior in Iranian women: A population-based study. J Res in Medical Sciences, 17.

O’Neill SC, Bowling JM, Brewer NT, et al (2008). Intentions to maintain adherence to mammography. J Women's Health, 17, 1133-41.

Poss JE (2001). Developing a new model for cross-cultural research: synthesizing the health belief model and the theory of reasoned action. Adv Nursing Science, 23, 1-15.

Povey R, Conner M, Sparks P, et al (2000). Application of the Theory of Planned Behaviour to two dietary behaviours: Roles of perceived control and self efficacy. $\mathrm{Br} J$ Health Psychol, 5, 121-39.

Preacher KJ, Hayes AF (2004). SPSS and SAS procedures for estimating indirect effects in simple mediation models. Behavior Research Methods, Instruments Computers, 36, 717-31.

Rakowski W, Breen N, Meissner H, et al (2004). Prevalence and correlates of repeat mammography among women aged 55-79 in the Year 2000 National Health Interview Survey. Preventive medicine, 39, 1-10.

Rakowski W, Meissner H, Vernon SW, et al (2006). Correlates of repeat and recent mammography for women ages 45 to 75 in the 2002 to 2003 Health Information National Trends Survey (HINTS 2003). Cancer Epidemiology Biomarkers Prevention, 15, 2093-101.

Russell KM, Champion VL, Skinner CS (2006). Psychosocial factors related to repeat mammography screening over 5 years in African American women. Cancer Nurs, 29, 236-43. Rutter D (2000). Attendance and reattendance for breast cancer 
Parvaneh Taymoori et al

screening: A prospective 3 year test of the Theory of Planned Behaviour. Br J Health Psychol, 5, 1-13.

Samah AA, Ahmadian M (2012). Socio-demographic correlates of participation in mammography: a survey among women aged between 35-69 in Tehran, Iran. Asian Pac J Cancer Prev, 13, 2717-20.

Sobel ME (1982). Asymptotic confidence intervals for indirect effects in structural equation models. Sociological methodol, 13, 290-312.

Taymoori P, Berry T, D R, et al (2013). Differences in health beliefs across stage of adoption of mammography in Iranian women. Cancer Nurs, 37, 208-17.

Taymoori P, Berry T (2009). The validity and reliability of champion's health belief model scale for breast cancer screening behaviors among Iranian women. Cancer Nurs, 32, 465 .

Taymoori P, Berry T, Farhadifar F (2012). Predicting mammography stage of adoption among Iranian women. $J$ Edu Health Promotion, 1, 13.

Thomas E, Escandón S, Lamyian M, et al (2011). Exploring Iranian women's perceptions regarding control and prevention of breast cancer. The Qualitative Report, 16, 1214-29.

Tolma EL, Reininger BM, Evans A, et al (2006). Examining the theory of planned behavior and the construct of self-efficacy to predict mammography intention. Health Education Behavior, 33, 233-51.

Witte K (1992). Putting the fear back into fear appeals: The extended parallel process model. Communications Monographs, 59, 329-49.

Yoo K-B, Kwon JA, Cho E, et al (2013). Is mammography for breast cancer screening cost-effective in both Western and Asian countries?: results of a systematic review. Asian Pac J Cancer Prev, 14, 4141-9. 